\title{
Comparison of optical coherence tomography findings in males and females with acute central serous chorioretinopathy
}

\author{
Feyza 'Çaliş Karanfil and Burak Turgut" \\ Yüksek İhtisas University, Faculty of Medicine, Department of Ophthalmology, Ankara, Turkey
}

\begin{abstract}
Objective: To compare the optical coherence tomography (OCT) findings in males and females with acute central serous chorioretinopathy (CSCR).

Materials and methods: In this retrospective study, the OCT scans of 8 females (Group 1) and 16 males (Group 2) cases with acute CSCR which were diagnosed based on clinical, ophthalmological and OCT findings and which was followed in our hospital were retrospectively reviewed. The existence of the OCT findings and patterns regarding CSCR and sub-foveal choroidal thicknesses (SFCTs) were compared.

Results: Serous macula detachment (SMD) was present in all of the female and male cases. The most common OCT finding was the brush-border pattern (6 cases, $75 \%)$ except SMD and retina pigment epithelium (RPE) bulging in females, and RPE bulging (14 cases, 87.5\%) except SMD in males. There was no statistically significant difference in the frequency of OCT findings and patterns between both groups ( $>0.05)$. The mean SFCTs of the eyes with CSCR in Group 1 and Group 2 were $346.08 \pm 32.1 \mu \mathrm{m}$ (ranged from 338 to $365 \mu \mathrm{m}$ ) and $351.32 \pm 36.5 \mu \mathrm{m}$ (ranged from 344 to $376 \mu \mathrm{m}$ ), respectively. The difference between SFCTs in the affected eyes was also not statistically significant $(\mathrm{p}>0.05)$.
\end{abstract}

Conclusion: This pilot study suggests that there is no difference between the frequencies of OCT findings and patterns of the female and male patients with acute CSCR.

\section{Introduction}

Central serous chorioretinopathy (CSC) is a common retinochoroidal disease characterized by serous detachment of the neurosensory retina and/or the retinal pigment epithelium (RPE) in the macula. It has a benign and self-limiting nature, with a long-term recurrence rate of $30 \%$. CSCR usually occur in males in 20-50 years [1-6].

Although the pathogenesis of disease is well unknown, it has been considered that focal RPE defect or choroidal lobular ischemia and choroidal venous congestion may be played in the main role [58]. Recent studies have demonstrated that the CSC is associated with psychological stress, type A personality, glucocorticoid treatment, endogenous hypercortisolism like Cushing's syndrome, systemic hypertension, and pregnancy [1-9].

Spectral domain optical coherence tomography (SD-OCT) is a very useful and a non-invasive imaging modality for the diagnosis and follow-up of various macular diseases.

In recent studies, the descriptive OCT findings in CSCR have been demonstrated in both sexuals [10-16]. However, to our best knowledge, there is not a direct comparison of the OCT findings between both sexual in the cases with CSCR in literature. Thus, we conducted this study to compare the OCT findings in male and female cases with acute CSCR.

\section{Material and methods}

This study was designed as a retrospective comparative study. In this retrospective study, the OCT scans of 8 female (Group 1) and 16 male (Group 2) cases with acute CSCR which were diagnosed based on clinical, ophthalmological and OCT findings and followed in retina section of our hospital were retrospectively reviewed. The study was designed according to Helsinki Declaration.

\section{Inclusion criteria}

Female (Group 1) and male (Group 2) patients with acute CSCR were included to the study. Acute CSCR was defined as the accumulation of serous fluid between the photoreceptor outer segments and the RPE and serous macular detachment (SMD) of the neurosensory retina selfresolving within 6 months of symptom onset.

\section{Exclusion criteria}

The patients with epi-retinal membrane or vitreo-macular traction documented by OCT, and media opacities such as corneal opacity, lens opacity, vitreous and pre-retinal haemorrhage, uveitis, choroidal neovascularization, diabetic maculopathy/retinopathy, and patients with history of previous intraocular surgery, macular laser photocoagulation, and intravitreal injection and the patients having

Correspondence to: Burak Turgut, Professor of Ophthalmology, Yuksek Ihtisas University, Faculty of Medicine, Department of Ophthalmology, 06520, Ankara, Turkey, Tel: +90 312 2803601; Fax: +90 3122803605; E-mail: burakturgut@yiu.edu.tr

Key words: central serous chorioretinopathy, acute, optical coherence tomography findings, males, females

Received: September 28, 2017; Accepted: October 24, 2017; Published: October 28,2017 
lower image quality score or low signal strength of OCT were excluded from the study.

\section{OCT procedure and analysis}

OCT examinations were performed using spectral OCT (RTVue-100 OCT, Optovue, Inc., Fremont, CA). During OCT examination the maculae were scanned by a single retina specialist (BT) on six radial sections including the horizontal, vertical, and oblique planes through the center of the fovea. Acquired OCT images were evaluated by the same retina specialist (BT). Sub-foveal choroidal thicknesses (SFCT) were measured manually by a single specialist (BT) using enhanced depth imaging (EDI) mode build-in the OCT device. Only following OCT findings to be attributed to acute CSCR but not chronic CSCR were evaluated [10-13, 16].

- Retina pigment epithelium detachment (PED) was defined as a dome-shaped elevation of the RPE typically seen overlying a homogeneously hypo-reflective space towards inner retina on RPEchoriocapillaris-Bruch membrane complex.

- The RPE bulging was defined as at least two sets of peaks and troughs of RPE or a small protrusion of the RPE layer (a slight elevation of the RPE without hypo-reflective space).

- Serous macula detachment (SMD) was defined as the domeshaped elevation of the posterior surface of the neurosensory retina over a nonreflective black cavity, with minimal shadowing of the underlying tissues and the presence of normal foveal pit but without shadowing in underlying tissues and destruction in the normal reflection of RPE.

- "Brush border pattern" or "elongation of photoreceptor outer segment" was defined as an irregular and serrated appearance on the outer surface of the detached neurosensory retina over subretinal fluid due to the accumulation of the waste products in photoreceptor outer segment.

- The intra-retinal hyper-reflective dot (IHRD) and sub-retinal hyperreflective dot (SHRD) were defined as hyper-reflective puncta in the detached neurosensory retina and under the outer surface of the detached retina, respectively.

- "Dipping (tenting down) pattern" was defined as triangular hyperreflective dipping or tenting down at the outer surface of detached neurosensory retina connecting the detached neurosensory retina and RPE. It was observed that the apex of this hyperreflective triangular entity was at RPE line while its base was at the detached retina.

\section{Statistical analysis}

Statistical analysis was performed using the Statistical Package for the Social Sciences (SPSS) version 11.0 (Chicago, IL, USA). Results were given as the means \pm standard deviations. The chi-square test was used to compare categorical variables in the study groups, respectively. A $P$ value less than 0.05 was considered as statistically significant.

\section{Results}

Group 1 included 8 women while Group 2 included 16 men. The mean ages of the Group 1 and Group 2 were $51 \pm 13.72$ years (ranging between 33 and 60 years) and $43.13 \pm 10.7$ (ranging between 34 and 60) years, respectively. The groups were matched for age and there was no statistically significant difference between the groups $(p>0.05)$. The optical coherence tomographical and demographical data in the study groups are given in Table 1
Table 1. The optical coherence tomographical and demographical data in the study groups.

\begin{tabular}{|l|l|l|l|}
\hline \multicolumn{1}{|l|}{} & Females $(\mathbf{N}=\mathbf{8})$ & \multicolumn{1}{|l|}{ Males $(\mathbf{N}=\mathbf{1 6})$} & P value \\
\hline Age (years) & $51.2 \pm 13.72$ & $43.13 \pm 10.7$ & $\mathrm{P}>0.05$ \\
\hline SMD (\%) & $8(100 \%)$ & $16(100 \%)$ & $\mathrm{P}>0.05$ \\
\hline PED & $0(0 \%)$ & $4(25 \%)$ & $\mathrm{P}>0.05$ \\
\hline Dipping pattern & $0(0 \%)$ & $0(0 \%)$ & $\mathrm{P}>0.05$ \\
\hline RPE bulging & $8(100 \%)$ & $14(87.5 \%)$ & $\mathrm{P}>0.05$ \\
\hline $\begin{array}{l}\text { Brush-border } \\
\text { pattern }\end{array}$ & $6(75 \%)$ & $6(37.5 \%)$ & $\mathrm{P}>0.05$ \\
\hline IHRD & $2(25 \%)$ & $4(25 \%)$ & $\mathrm{P}>0.05$ \\
\hline SRHRD & $0(0 \%)$ & $2(12.5 \%)$ & $\mathrm{P}>0.05$ \\
\hline $\begin{array}{l}\text { Choroidal } \\
\text { Thickness }\end{array}$ & $346.08 \pm 32.1 \mu \mathrm{m}$ & $351.32 \pm 36.5 \mu \mathrm{m}$ & $\mathrm{P}>0.05$ \\
\hline
\end{tabular}

\section{OCT findings}

OCT imaging in female cases revealed that there were single SMD in 8 cases $(100 \%)$, PED with SMD in 0 case ( $0 \%)$, RPE bulging with SMD in 8 cases $(100 \%)$, brush-border pattern with SMD in 6 cases (75\%), dipping pattern with SMD in 0 case $(0 \%)$, IHRDs with SMD in 2 cases $(25 \%)$ and SHRDs with SMD in 0 cases ( $0 \%)$.

In OCT scans in males with CSCR, it was detected single SMD in 16 cases (100\%), PED with SMD in 4 cases (25\%), RPE bulging with SMD in 14 cases $(87.5 \%)$, brush-border pattern with SMD in 6 cases (37.5\%), dipping pattern with SMD in 0 case (0\%), IHRDs with SMD in 4 cases $(25 \%)$ and SHRDs with SMD in 2 cases (12.5\%). There was no statistically significant difference in OCT findings and patterns between both groups $(\mathrm{p}>0.05)$. The most common OCT finding except SMD was the brush-border pattern $(75 \%)$ in females and RPE bulging $(87.5 \%)$ in males.

The mean SFCTs of the affected eyes in Group 1 and Group 2 were $346.08 \pm 32.1 \mu \mathrm{m}$ (ranged from 338 to $365 \mu$ ) and $351.32 \pm 36.5 \mu \mathrm{m}$ (ranged from 344 to 376 ), respectively. The difference between SFCTs in the affected eyes was not statistically significant $(\mathrm{p}>0.05)$.

Additionally, the mean SFCTs in the un-effected opposite eyes in Group 1 and Group 2 were $256.22 \pm 19.60 \mu \mathrm{m}$ (ranged from 236 to $343 \mu \mathrm{m}$ ) and $246.11 \pm 26.5 \mu \mathrm{m}$ (ranged from 229.7 to 356 ), respectively. It was detected that the difference in SFCTs in the un-effected eyes in both groups was not statistically significant $(\mathrm{p}>0.05)$.

\section{Discussion}

The most common spectral domain OCT findings detected in the patients with acute CSCR are PED, RPE bulging, SMD, dipping pattern, brush-border pattern or elongation of photoreceptor outer segments and IHRDs or SHRDs [2,13,17-21].

In a meta-analytic comprehensive review, Daruich et al presented the frequencies of these OCT findings in acute CSCR as follows: the elevation or bulging of RPE 19-68\%, PED 32-71\%, SHRDs 20.3-52\%, sagging or dipping pattern $13-43 \%$, elongated photoreceptor outer segments or brush-border pattern $73 \%$, SHRDs $65 \%-82 \%$, IHRDs $21-100 \%$ [2]. However, PED prevalence may vary from $8 \%$ to $71 \%$ $[11,18,19,22]$. In our study, OCT did not show any PED in female cases. This is very interesting finding to be considered in the comparison of OCT findings in both sexual.

Fundus angiography (FA) and OCT studies showed that both PED and the small bump/bulging areas are consistent with the leakage points localization of the defect, thickening, or protrusion in the RPE in the FA in active CSCR [2,5,10-16,23]. These bulging lesions should not be confused with PED. Hirami et al reported that the RPE bulging was 
presented in $89 \%$ of the patients and that these were located in areas of choroidal vascular hyperpermeability [24]. Montero et al reported that the hyperreflective small RPE bulging is present in $90 \%$ of the cases and they were related to leaking spots in FA [11]. However, it has been reported in an en face OCT study that it was detected in $35 \%$ of the eyes with acute CSCR [19]. Additionally, RPE layer mapping study using OCT demonstrated that RPE bulging was in $94 \%$ of asymptomatic eyes in patients with CSR [25]. RPE bulging was observed in all of the females and a percent of 87.5 in males in our study. This is compatible with previous reports.

Hyperreflective spots or dots (HRD) are new findings previously unseen in OCT demonstrated firstly by Coscas et al [26]. The HRDs are scattered, punctiform, small in size, mainly located in the outer retinal layers. It has been reported in the patients with CSCR. It has been demonstrated that HRDs in the patients with CSCR may be located as subretinal, intraretinal or at inner regions of the detached retina $[13,17,26,27]$. Although etiology of HRD is not clear, there are various theories of the pathogenesis of HRD. They might be caused focal accumulations of pigment or lipofuscin granules, small intraretinal proteins or lipid/lipoprotein exudates/deposits/extravasation due to the breakdown of the blood-retinal barrier, derived the degenerated photoreceptors or the macrophages phagocyted their outer segments. It has been suggested that HRD might be a marker of the inflammatory response or the breakdown of the blood-retina barrier [13,17,26,27]. OCT showed that HRDs accumulate at the posterior surface of the detached neurosensory retina in a vast majority of the patients with CSCR and that HRDs might have non-phagocyte-bearing rhodopsin and/or due to previous inflammatory mediators and/or dysfunctional RPE [28]. In our study, we observed IHRDs in $25 \%$ of the cases while as we did not detect any SHRD in female cases. However, $25 \%$ of male cases had IHRD and $12.5 \%$ of males had SHRDs. These prevalences seem lower compared to previous reports. This may be related to the evaluation of only acute CSCR cases in our study.

Dipping (tenting down) pattern may be observed in some acute CSCR patients. It is characterized by dipping or tenting at the outer surface of the detached neurosensory retina due to hyper-reflective material accumulation such as sub-retinal fibrin or fibrinous exudate connecting the detached neurosensory retina and RPE at its opposite $[13,17,29]$. In our study, OCT did not reveal dipping pattern in any case. This may be due to the absence of chronic recurrent cases in our study.

Brush-border pattern or elongation of photoreceptor outer segments is due to the accumulation of the waste products in photoreceptor outer segments and also the elongation of photoreceptor outer segments. In the normal turn, waste products of photoreceptors are removed by RPEs via phagocytosis. However, in CSCR, sub-retinal fluid and serous macular detachment cause loss of the contact between photoreceptor outer segments and RPE. Thus, waste products in photoreceptor outer segments accumulate on the outer surface of the detached neurosensory retina. This provides an irregular appearance of the detached neurosensory retina [10-13 16,18-20,30]. In the other hand, intraretinal precipitates may result from proteins or accumulation of macrophages that may have phagocytized photoreceptor outer segments [16]. The most common finding except SMD in OCT was the brush-border pattern $(75 \%)$ in female cases in our study.

Although there is no descriptive and comparative study in literature belonging to only female case group with CSCR, some case reports present OCT findings in females with CSCR. In the acute stage of the disease, it has been observed sub-retinal hyper-reflective material except for SMD [24].
In previous reports, it has been considered that CSCR in women was associated with subretinal precipitates and absence of PED or longer duration for development of PED [31-38]. The absence of PED in OCT examinations in female cases as seen in our study is compatible with this association.

In conclusion, this pilot study suggests that there is no difference between the frequencies of OCT findings and patterns of the female and male patients with acute CSCR. However, female patients with CSCR are usually presented with RPE bulging but not PED compared to the males. Further studies are needed to understand the exact cause of presentation finding in female cases.

\section{Acknowledgments}

Involved in the conduct of the study; the collection of data, typing, and editing of the manuscript; statistical analysis and editing of the manuscript and preparation, review, or approval of the final manuscript (FÇK, BT).

\section{References}

1. Yannuzzi LA (1987) Type-A behavior and central serous chorioretinopathy. Retina 7: 111-131. [Crossref]

2. Daruich A, Matet A, Dirani A, Bousquet E, Zhao M, et al. (2015) Central serous chorioretinopathy: Recent findings and new physiopathology hypothesis. Prog Retin Eye Res 48: 82-118. [Crossref]

3. Wang M, Munch IC, Hasler PW, Prünte C, Larsen M (2008) Central serous chorioretinopathy. Acta Ophthalmol 86: 126-145. [Crossref]

4. Liegl R, Ulbig MW (2014) Central serous chorioretinopathy. Ophthalmologica 232 65-76. [Crossref]

5. Nicholson B, Noble J, Forooghian F, Meyerle C (2013) Central serous chorioretinopathy: update on pathophysiology and treatment. Surv Ophthalmol 58: 103-126. [Crossref]

6. Abouammoh MA (2015) Advances in the treatment of central serous chorioretinopathy. Saudi J Ophthalmol 29: 278-286. [Crossref]

7. Prünte C, Flammer J (1996) Choroidal capillary and venous congestion in central serous chorioretinopathy. Am J Ophthalmol 121: 26-34. [Crossref]

8. Iida T, Kishi S, Hagimura N, Shimizu K (1999) Persistent and bilateral choroida vascular abnormalities in central serous chorioretinopathy. Retina 19: 508-512. [Crossref]

9. Gass JDM. (1991) Central serous chorioretinopathy and white subretinal exudation during pregnancy. Arch Ophthalmol 109: 677-681. [Crossref]

10. Ojima Y, Hangai M, Sasahara M, Gotoh N, Inoue R, et al. (2007) Three-dimensiona imaging of the foveal photoreceptor layer in central serous chorioretinopathy using high-speed optical coherence tomography. Ophthalmology 114: 2197-2207. [Crossref]

11. Montero JA, Ruiz-Moreno JM (2005) Optical coherence tomography characterization of idiopathic central serous chorioretinopathy. Br J Ophthalmol 89: 562-564. [Crossref]

12. Iida T, Hagimura N, Sato T, Kishi S (2000) Evaluation of central serous chorioretinopathy with optical coherence tomography. Am J Ophthalmol 129: 16-20. [Crossref]

13. Turgut B, Ergen I (2013) Santral seröz koryoretinopatinin optik koherens tomografik paternleri (Optical Coherence Tomographic Patterns of Central Serous Chorioretinopathy). Firat Medical Journal 18: 39-43.

14. Rezai KA, Eliott D (2004) Optical coherence tomographic findings in pregnancyassociated central serous chorioretinopathy. Graefes Arch Clin Exp Ophthalmol 242 1014-1016. [Crossref]

15. Theodossiadis PG, Kollia AK, Gogas P, Panagiotidis D, Moschos M, et al. (2002) Retinal disorders in preeclampsia studied with optical coherence tomography. Am J Ophthalmol 133: 707-709. [Crossref]

16. Kon Y, Iida T, Maruko I, Saito M (2008) The optical coherence tomographyophthalmoscope for examination of central serous chorioretinopathy with precipitates. Retina 28: 864-869. [Crossref]

17. Turgut B, Demir T (2016) The new landmarks, findings and signs in optical coherence tomography, New Front Ophthalmol 2: 131-136. 
18. Mitarai K, Gomi F, Tano Y (2006) Three-dimensional optical coherence tomographic findings in central serous chorioretinopathy. Graefes Arch Clin Exp Ophthalmol 244: 1415-1420. [Crossref]

19. Fujimoto H, Gomi F, Wakabayashi T, Sawa M, Tsujikawa M, et al (2008) Morphologic changes in acute central serous chorioretinopathy evaluated by fourier-domain optical coherence tomography. Ophthalmology 115: 1494-1500. [Crossref]

20. Kim HC, Cho WB, Chung H (2012) Morphologic changes in acute central serous chorioretinopathy using spectral domain optical coherence tomography. Korean $J$ Ophthalmol 26: 347-354. [Crossref]

21. Shin YU, Lee BR (2012) Retro-mode Imaging for retinal pigment epithelium alterations in central serous chorioretinopathy. Am J Ophthalmol 154: 155-163. [Crossref]

22. Van Velthoven MEJ, Verbraak FD, Garcia PM, Schlingemann RO, Rosen RB, de Smet MD (2005) Evaluation of central serous retinopathy with en face optical coherence tomography. Br J Ophthalmol 89: 1483-1488. [Crossref]

23. Lehmann M, Wolff B, Vasseur V, Martinet V, Manasseh N, Sahel JA, Mauget-Faysse M (2013) Retinal and choroidal changes observed with 'En face' enhanced-depth imaging OCT in central serous chorioretinopathy. Br J Ophthalmol 97: 1181-1186. [Crossref]

24. Hirami Y, Tsujikawa A, Sasahara M, Gotoh N, Tamura H, et al. (2007) Alterations of retinal pigment epithelium in central serous chorioretinopathy. Clin Exp Ophthalmol 35: 225-230. [Crossref]

25. Gupta P, Gupta V, Dogra MR, Singh R, Gupta A (2010) Morphological changes in the retinal pigment epithelium on spectral-domain OCT in the unaffected eyes with idiopathic central serous chorioretinopathy. Int Ophthalmol 30: 175-181. [Crossref]

26. Coscas G, De Benedetto U, Coscas F, Li Calzi CI, Vismara S, et al (2013) Hyperreflective dots: a new spectral-domain optical coherence tomography entity for follow-up and prognosis in exudative age-related macular degeneration. Ophthalmologica 229: 3237. [Crossref]

27. Turgut B, Yildirim H (2015) The causes of hyperreflective dots in optical coherence tomography excluding diabetic macular edema and retinal venous occlusion§. Open Ophthalmol J 9: 36-40. [Crossref]
28. Ahlers C, Geitzenauer W, Stock G, Golbaz I, Schmidt-Erfurth U, et al. (2009) Alterations of intraretinal layers in acute central serous chorioretinopathy. Acto Ophthalmol 87: 511-516. [Crossref]

29. Hussain N, Baskar A, Ram LM, Das T (2006) Optical coherence tomographic pattern of fluorescein angiographic leakage site in acute central serous chorioretinopathy. Clin Exp Ophthalmol 34: 137-140. [Crossref]

30. Matsumoto H, Kishi S, Otani T, Sato T (2008) Elongation of photoreceptor outer segment in central serous chorioretinopathy. Am J Ophthalmol 145: 162-168. [Crossref]

31. Gobuty M, Adhi M, Duker JS (2013) Central serous chorioretinopathy in a 91-year-old woman. Br J Ophthalmol 97: 1607-1608, 1615-6. [Crossref]

32. Said-Ahmed K, Moustafa G, Fawzy M (2012) Incidence and Natural Course of Symptomatic Central Serous Chorioretinopathy in Pregnant Women in a Maternity Hospital in Kuwait. Middle East Afr J Ophthalmol 19:273-276. [Crossref]

33. Quillen DA, Gass DM, Brod RD, Gardner TW, Blankenship GW, et al. (1996) Central serous chorioretinopathy in women. Ophthalmology 103: 72-79. [Crossref]

34. Al-Mujaini A, Wali U (2014) Alternating central serous chorioretinopathy in two consecutive pregnancies. Oman J Ophthalmol 7: 87-89. [Crossref]

35. Musetti D, Nicolo M, Traverso C (2013) Central serous chorioretinopathy in women Invest Ophthalmol Vis Sci. 54: 3842.

36. Lin D, Chen W, Zhang G, Huang H, Zhou Z, et al (2014) Comparison of the optical coherence tomographic characters between acute Vogt-Koyanagi-Harada disease and acute central serous chorioretinopathy. BMC Ophthalmol 14:87. [Crossref]

37. Perkins SL, Kim JE, Pollack JS, Merrill PT (2002) Clinical characteristics of central serous chorioretinopathy in women. Ophthalmology 109: 262-266. [Crossref]

38. Uhumwangho OM, Momoh RO (2015) Central serous chorioretinopathy in Benin City, Nigeria. Ann Afr Med 14: 163-168. [Crossref]

Copyright: (C)2017 Çaliş Karanfil F. This is an open-access article distributed under the terms of the Creative Commons Attribution License, which permits unrestricted use, distribution, and reproduction in any medium, provided the original author and source are credited. 